\title{
The role of the urban family physician plan in utilization of outpatient services in Iran
}

\author{
MOBIN SOKHANVAR ${ }^{1, A, E, F}$, MOHAMMAD JAVAD KABIR ${ }^{2, F, G}$, HOSSEIN BEVRAN $\left.\right|^{3, c, D}$, \\ SHIRIN NOSRATNEJAD ${ }^{1, B, C, D}$, EDRIS HASANPOOR ${ }^{4, D-F}$, ALI JANATI $^{5, A, E-G}$ \\ ORCID ID: 0000-0003-2600-2234
}

\author{
${ }^{1}$ Iranian Center of Excellence in Health Management, School of Management and Medical Informatics, Tabriz \\ University of Medical Sciences, Tabriz, Iran \\ ${ }^{2}$ Health Management and Social Development Research Center, Golestan University of Medical Sciences, Gorgan, \\ Iran \\ ${ }^{3}$ Department of Statistics, Faculty of Mathematical Sciences, University of Tabriz, Tabriz, Iran \\ ${ }^{4}$ Department of Healthcare Management, Research Center for Evidence-Based Health Management, Maragheh \\ University of Medical Sciences, Maragheh, Iran \\ ${ }^{5}$ School of Management and Medical Informatics, Tabriz University of Medical Sciences, Tabriz, Iran
}

A - Study Design, B - Data Collection, C - Statistical Analysis, D - Data Interpretation, E - Manuscript Preparation, F - Literature Search, G - Funds Collection

Summary Background. The family physician (FP) is vital for the continuity of care (CoC) and is also a reliable guide in choosing the preferred treatment pathways, which lead to a reduction in the utilization of unnecessary services.

Objectives. To investigate the utilization of outpatient services in the Fars province as a pilot center for the urban family physician program (UFPP) and East Azerbaijan. East Azerbaijan is a province which has been selected for comparison (control) through clustering. Material and methods. This population-based, comparative and cross-sectional study was conducted in Iran. Retrospective data on specialists/subspecialists visits (SSV), prescribed medicine (PM), laboratory services (LS) and medical imaging services (MIS) was obtained from administrative claims data of the Iranian Health Insurance Organization (IHIO) for a random sample of 4,800 people between September 2017 and September 2018.

Results. Overall, $50.2 \%$ of the participants were female. In the Fars province, the mean SSV, PM, LS and MIS utilization during the study period was $1.21,3.05,0.49$, and 0.29 , respectively. These amounts were 1.14, 1.71, 0.36 and 0.21 , respectively, in East Azerbaijan. Multivariate analysis showed significant differences in the utilization of SSV, PM, LS and MIS between provinces $(p<0.05)$. The largest difference was observed in the utilization of PM by a mean difference of $1.33(1.17-1.50, p<0.001)$. Females were associated with more PM utilization $(p=0.003)$, and older people utilized more outpatient services $(p<0.05)$.

Conclusions. Unexpectedly, after five years of the implementation of UFPP, utilization of services was higher in Fras than East Azerbaijan. Improved access by removing barriers, especially for women and the poor, as well as program execution problems could be the reason for these results. Further research is urgently needed to solve this mystery.

Key words: primary health care, family physician, referral system and consultation, outpatients, utilization review.

Sokhanvar M, Kabir MJ, Bevrani H, Nosratnejad S, Hasanpoor E, Janati A. The role of the urban family physician plan in utilization of outpatient services in Iran. Fam Med Prim Care Rev 2020; 22(4): 331-337, doi: https://doi.org/10.5114/fmpcr.2020.100444.

\section{Background}

Primary health care (PHC) was proposed as a panacea to achieving "health for all" in 1978 following the Declaration of Alma-Ata [1]. After three decades, PHC was again introduced as a way of making health systems into a more efficient, effective and fairer system in a world health report in 2008 [2]. PHC can be provided effectively via a family physician program (FPP) and improve effectiveness, efficiency, quality and equality [3]. The history of implementing FPP within an appropriate referral system, which links different levels of the healthcare system, has shown the systems' success in improving efficiency [4-6]. This can be achieved by promoting community health and reducing the costs of specialized services, which are themselves driven by improvements in quality, coordination, integrity and $\operatorname{CoC}[5,7,8]$.

\section{Urban family physician program in Iran}

Healthcare in Iran has experienced some reforms, following the Iranian revolution in 1979, to provide the global goal of
"Health for All, 2000" [9]. One of the most influential reforms, in the field of PHC, was the establishment of a national health network in 1984 [10]. This reform had major implications over the past few decades in improving access, quality, health promotion and equality $[10,11]$. The responsibility of the rural health centers (RHCs) and urban health centers (UHCs) within this network was borne by general practitioners that were almost an example of "Gatekeepers" [12]. Currently, the health system has three levels. PHC is provided at the first level (level-I) for rural and urban areas. The second and third levels (level-II and level-III) are specialized, and hospital services are provided in large counties and in provincial centers $[13,14]$.

Emphasizing the implementation of FPP in Third, Fourth and Fifth national strategic program on Iran's economy, social and cultural development, the rural family physician program (RFPP) has been implemented since 2005 in rural and urban areas with a population less than 20,000 [15]. After several years of running RFPP, UFPP started as a pilot project in the urban areas (population more than 20,000 ) of two provinces, Fars and 
Mazandaran, from the $8^{\text {th }}$ of July 2012 . The IHIO is obliged to finance and implement the UFPP for insurers, covered by itself (41\% of the total Iranian population) and others who enroll in the program [13].

Within UFPP, a team consisting of nurses, public health professions and midwiferies provides PHC services for clients who are registered in the program. To ensure $\mathrm{CoC}$, patients were referred to level-II and level-III to receive specialized services within the referral system [16]. Per capita, fee-for-service, per case and bonus are the payment mechanisms used in UFPP. Most of the services in level-I are free, or, in some cases, patients pay a small share. Specialist level services (level-II and level-III) are provided low out-of-pocket payments by patients for whom using the referral system. However, the use of the referral system is not mandatory, and there is the possibility of self-referral, of course, by paying a high share of the cost of services (70-100\% according to the type of services and providers) $[16,17]$.

\section{The consequences of UFPP}

Globally, one of the areas investigated regarding the consequences of FPP is utilization rate and health expenditures [5, 7, 17-21]. Starfield et al. argued that FPP can reduce the cost by providing better quality and reducing unnecessary specialist care [5]. The amount of this decline in utilization of health services and its economic burden is estimated at 78 and $80 \%$, respectively [18]. In Saudi Arabia, the establishment of a referral system has reduced outpatient appointments by $40 \%$ in specialized centers [19]. This is while all the evidence does not confirm the decreasing effect of FPP and referral system about costs and service utilization $[20,21]$. Thanh and Rapoport concluded that people with a regular doctor used more health care than others [20]. Analyses performed on health care expenditure in 18 OECD countries also showed no significant effects of gatekeeping on health care expenditure [21].

There is slight evidence in Iran about the effects of UFPP on utilization of services. Studies that examined the status of access to care and $\mathrm{CoC}$ have shown improvement in some aspects, included geographical and organizational access, registering patients' clinical information, establishing a health information database and developing and expanding the referral system. Nevertheless, it has not been possible to reach a definitive conclusion about the positive outcome of the program in these areas because of the problems that still exist [22, 23]. It is well documented that $\mathrm{CoC}$ can lead to reduced unnecessary utilization [24, 25].

In Iran, according to Heshmati and Joulaei, estimates regarding the effect of UFPP on service utilization are not reliable due to the possibility of self-referral [10]. In 2015, in the Fars province, a total of $70.3 \%$ of patients had used the referral system to visit specialists, which means that the remaining $29.7 \%$ were self-referrals [26]. The results of a study conducted in urban areas of Shiraz (the center of the Fars province) in 2016 revealed a reduction in the utilization of laboratory services by $3 \%$ in public centers and $18 \%$ in private centers after implementation of UFPP. The utilization of medical imaging tests was also decreased by 6 and $21 \%$ in public and private centers, respectively [27].

Little evidence and no comparison with matched environments do not allow for the proper analysis of the utilization rates. Therefore, this study aimed to investigate the utilization of outpatient services in the Fars province as a pilot center for UFPP and in East Azerbaijan. East Azerbaijan is a province which has been selected for comparison (control) through clustering.

\section{Material and methods}

\section{Study design and setting}

A population-based, comparative and cross-sectional study was conducted in 2019. Retrospective data was obtained from the electronic medical record of the IHIO between September 2017 and September 2018.

Iran is located within the Eastern Mediterranean Region (EMR) of the WHO (World Health Organization) [28] and has a population of 79,926,270 (last census in 2015) and is geographically divided into 31 provinces. Fars and Mazandaran are two provinces in which UFPP has been implemented as a pilot program in their urban areas since 2012 . The Fars province was selected by simple random selection and a matched province was selected through clustering to provide comparability. A set of indicators, including urban population covered by the IHIO, the number of general practitioners, the number of specialists and subspecialists, the number of medical centers having a contract with the IHIO, the economic participation rate of the province, the employment rate, the rate of literacy and the annual cost and income of the urban households, was used [29,30]. In this study, the Davis-Bouldin Index was used to validate clustering and determine the favorable number of clusters [31]. Based on the results, the most favorable was a number of four clusters. Accordingly, Fars, along with seven other provinces (Mazandaran, East Azerbaijan, West Azerbaijan, Esfahan, Khuzestan, Gilan and Khorasan Razavi), was located in the same cluster. From the other seven provinces (except Mazandaran), East Azerbaijan was selected randomly. Fars and East Azerbaijan, as two of the biggest Iranian provinces, have a population of 3,909,652 and $4,851,274$, respectively $(10.96 \%$ of the total population of the country). In each province, five counties were randomly selected (Figure 1). Accordingly, the counties of Tabriz, Maragheh, Osku, Ajabshir and Shabestar, which comprise $61.4 \%$ of the province's population, were selected. Shiraz, Farashband, Abadeh, Neyriz and Zarin Dasht were five selected counties from the Fars province, with a $38.8 \%$ share of the province's total population.
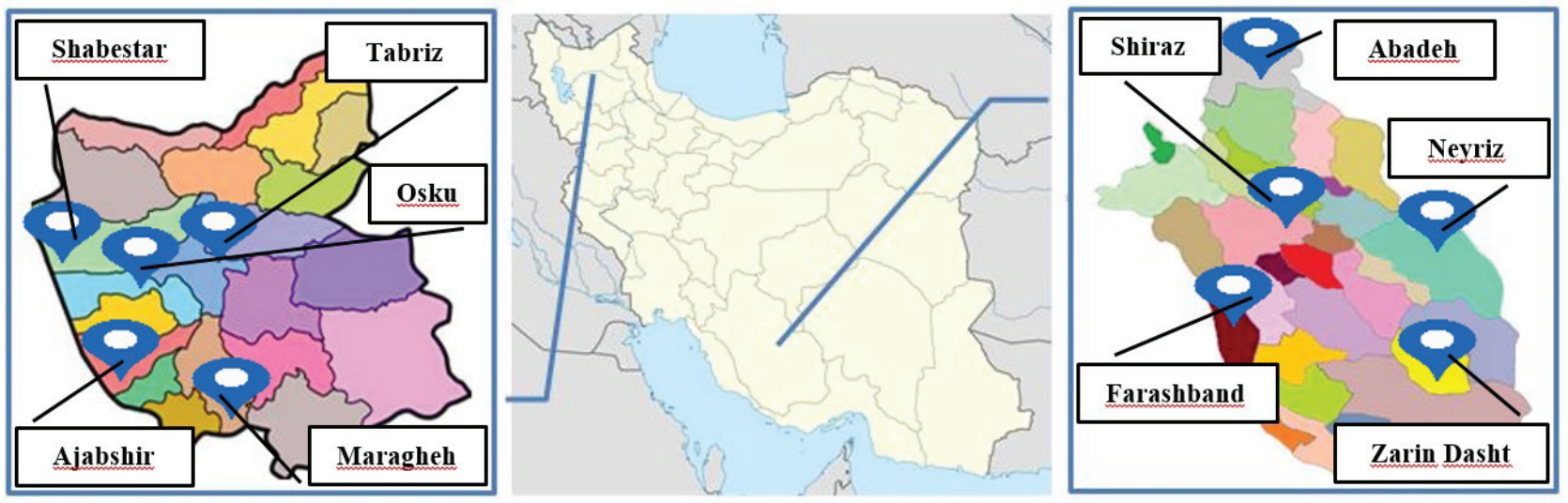

Figure 1. Selected counties of the Fars and East Azerbaijan provinces 


\section{Participants}

The study population consisted of residents in urban areas (population $>20,000$ ) of the two selected provinces that were insured by the IHIO during the data collection period. Sample size was calculated to be 384 persons from each county to achieve $95 \%$ confidence with $5 \%$ margin of error. Selection of the sample from the study population was carried out by means of systematic random sampling method based on the code of health insurance of individuals.

\section{Variables}

The utilization rate was extracted retrospectively for a one-year period from September 2017 to September 2018. The services received by outpatients in level-II and level-III were investigated. In this regard, the main frequent outpatient services were selected, which included SSV, PM (the number of prescriptions given during the period), LS (the number of those referring to a laboratory to perform one or more laboratory tests prescribed in one doctor's order) and MIS (such ST. Scan, MRI, etc., each prescribed in a separate order). Age and gender (demographic variables), which are available in the IHIO database, were also extracted.

\section{Statistical methods}

The K-means method was used for clustering by Rapid Miner software (Rapid Miner version 4.1 Beta 2, 2001-2007). The age and gender of enrollees were compared among the two provinces by using the Chi-square test. The independent sample $t$-test was used to examine the province's difference in the utilization of four types of services. In order to investigate the association between independent variables, including province (which is related to having or not having urban FP), age and gender, with the utilization of services, the general linear model (GLM) multivariate analysis of variance (MANOVA) was applied. This statistical approach can be used to test the hypothesis of a significant association between a set of interrelated dependent variables [32]. The independent variables analyzed in the present study consisted of the province (Fars vs East Azerbaijan, which directly indicates the presence or absence of an urban FP), gender (male vs female) and age (1-18 vs $19-25$ vs $26-35$ vs $36-45$ vs $46-55$ vs $56-65$ vs $>65$ ). Tukey's post hoc test was applied to determine the source of differences in cases where significant differences were observed between groups. SPSS 23.0 (SPSS, Inc., Chicago, IL, USA) was used to analyze the data.

\section{Ethics approval}

Ethical approval was obtained from the Ethical Committee of Research, Vice-Chancellor of Tabriz University of Medical Sciences (IR.TBZMED.REC.1396.835). In addition, data was obtained anonymously from the electronic medical record of the IHIO.

\section{Results}

The data of a total of 4,800 people was obtained, of which 2,300 individuals $(47.9 \%$ of the total sample) were from Fars (Shiraz (600, 26.1\%), Farashband (400, 17.4\%), Abadeh (500, 21.7\%), Neyriz $(400,17.4 \%)$ and Zarin Dasht $(400,17.4 \%))$, and another 2,500 individuals were from East Azerbaijan (500 people from each county). The mean age was 36.7 years (SD = 20.1). According to the results of the chi-square test presented in Table 1, there was a significant difference between the two studied provinces regarding the samples' age, but no such difference was observed in terms of gender (Table 1).

\begin{tabular}{|c|c|c|c|c|}
\hline \multirow[t]{2}{*}{$\begin{array}{l}\text { Character- } \\
\text { istics }\end{array}$} & Fars & $\begin{array}{l}\text { East Azerbai- } \\
\text { jan }\end{array}$ & \multirow[t]{2}{*}{$x^{2}$} & \multirow[t]{2}{*}{ Sig. } \\
\hline & No (\%) & No (\%) & & \\
\hline $\begin{array}{c}\text { Age (years) } \\
1-18 \\
19-25 \\
26-35 \\
36-45 \\
46-55 \\
56-65 \\
65<\end{array}$ & $\begin{array}{l}493(21.4) \\
278(12.1) \\
499(21.7) \\
330(14.3) \\
286(12.4) \\
239(10.4) \\
175(7.6)\end{array}$ & $\begin{array}{l}434(17.4) \\
272(10.9) \\
571(22.8) \\
407(16.3) \\
314(12.6) \\
219(8.8) \\
283(11.3)\end{array}$ & \multirow[t]{2}{*}{36.087} & \multirow[t]{2}{*}{$<0.001$} \\
\hline Total & $2,300(100.0)$ & $2,500(100.0)$ & & \\
\hline $\begin{array}{c}\text { Gender } \\
\text { male } \\
\text { female }\end{array}$ & $\begin{array}{l}1,157(50.3) \\
1,143(49.7)\end{array}$ & $\begin{array}{l}1,253(50.1) \\
1,247(49.9)\end{array}$ & \multirow[t]{2}{*}{0.016} & \multirow[t]{2}{*}{0.898} \\
\hline Total & $2,300(100.0)$ & $2,500(100.0)$ & & \\
\hline
\end{tabular}

The mean and standard deviation of utilization of services in the studied provinces are shown in Table 2 . The mean of the utilization of PM, LS and MIS was significantly higher among outpatients of the Fars province $(p<0.05)$. The largest differences were observed in the utilization of PM, i.e. people in the Fars province utilize more PM than other enrollees from East Azerbaijan by a minimum of 1.17 and a maximum of 1.50 per year.

The results of the multivariate analysis are shown in Table 3. In the first step of the GLM-MANOVA, the association between the independent variables (province and gender) and the dependent variables (SSV, PM, LS and MIS) was investigated by applying the one-factor model (Table 3 ). In this stage, the results showed a significant association between the province and three of the four outcomes (PM, LS and MIS) $(p<0.05)$. There was a significant association between gender and prescribed medicines, and a significant association was also shown between age and utilization of the four studied services $(p<0.05)$.

The three independent variables were then entered into the multifactor model analysis, which indicated that the variables of gender and age remained significant (Table 3). A significant association was also shown between the province and utilization of SSV, PM, LS and MIS $(p<0.05)$. Tukey's post hoc regarding the province variable showed that the utilization rate was sig-

\begin{tabular}{|c|c|c|c|c|c|c|}
\hline \multirow[t]{2}{*}{ Services } & \multirow{2}{*}{$\frac{\text { Fars }}{\text { Mean } \pm \text { SD }}$} & \multirow{2}{*}{$\begin{array}{l}\text { East Azerbaijan } \\
\text { Mean } \pm \text { SD }\end{array}$} & \multicolumn{4}{|c|}{ Test results } \\
\hline & & & $t$ & Sig. & MD* & $95 \% \mathrm{Cl}^{* *}$ \\
\hline SSW & $1.21 \pm 2.38$ & $1.14 \pm 1.67$ & 1.20 & 0.228 & 0.07 & $-0.04-0.18$ \\
\hline PM & $3.05 \pm 3.71$ & $1.71 \pm 1.61$ & 15.95 & $<0.001$ & 1.33 & $1.17-1.50$ \\
\hline LS & $0.49 \pm 1.01$ & $0.36 \pm 0.71$ & 5.02 & $<0.001$ & 0.12 & $0.07-0.17$ \\
\hline MIS & $0.29 \pm 0.77$ & $0.21 \pm 0.54$ & 3.95 & $<0.001$ & 0.07 & $0.03-0.11$ \\
\hline
\end{tabular}

*MD - mean difference; $\mathrm{Cl}$ - confidence interval. 


\begin{tabular}{|c|c|c|c|c|c|c|c|c|c|}
\hline \multicolumn{2}{|l|}{ Variables } & \multicolumn{4}{|c|}{ One-factor* } & \multicolumn{4}{|c|}{ Multifactor** } \\
\hline & & SSV & PM & LS & MIS & SSV & PM & LS & MIS \\
\hline \multirow[t]{3}{*}{ Province } & Wilk's $\lambda$ & \multicolumn{4}{|l|}{0.942} & \multicolumn{4}{|l|}{0.938} \\
\hline & $F$ & 1.49 & 269.42 & 25.95 & 16.07 & 5.54 & 290.01 & 38.49 & 28.45 \\
\hline & Sig. & 0.221 & $<0.001$ & $<0.001$ & $<0.001$ & 0.019 & $<0.001$ & $<0.001$ & $<0.001$ \\
\hline \multirow[t]{3}{*}{ Gender } & Wilk's Wilk's $\lambda$ & \multicolumn{4}{|l|}{0.997} & \multicolumn{4}{|l|}{0.998} \\
\hline & $F$ & 1.18 & 13.22 & 0.47 & 2.96 & 1.15 & 9.98 & 0.01 & 1.93 \\
\hline & Sig. & 0.278 & $<0.001$ & 0.491 & 0.085 & 0.284 & 0.003 & 0.900 & 0.165 \\
\hline \multirow[t]{3}{*}{ Age } & Wilk's Wilk's $\lambda$ & \multicolumn{4}{|l|}{0.985} & \multicolumn{4}{|l|}{0.983} \\
\hline & $F$ & 3.66 & 4.86 & 5.57 & 4.15 & 3.90 & 5.15 & 6.16 & 5.20 \\
\hline & Sig. & 0.001 & $<0.001$ & $<0.001$ & $<0.001$ & 0.001 & $<0.001$ & $<0.001$ & $<0.001$ \\
\hline
\end{tabular}

* Only one independent variable was entered into the model per each analysis, ${ }^{* *}$ all independent variables were entered.

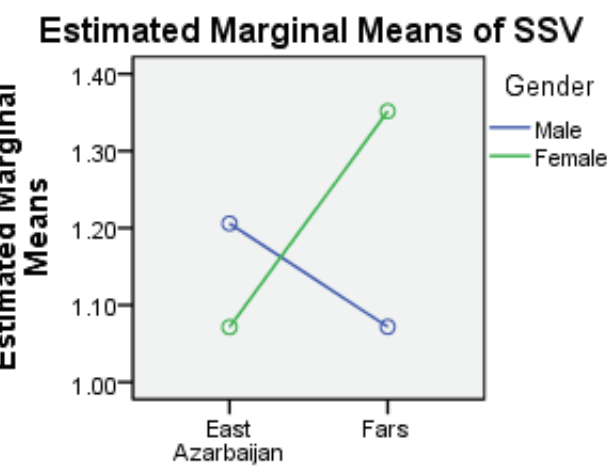

Province

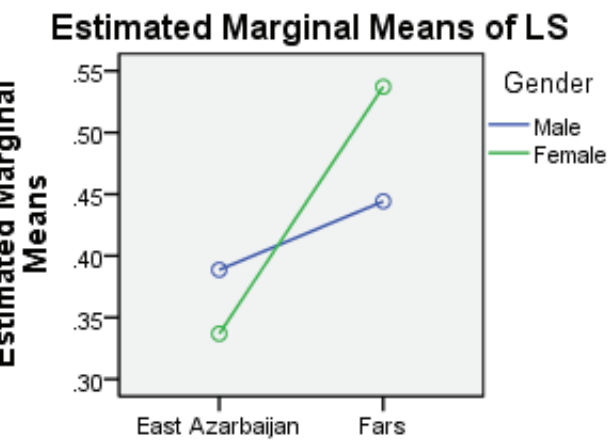

Province

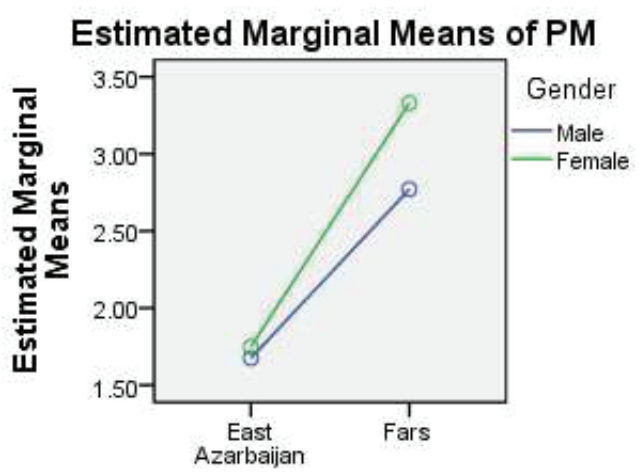

Province

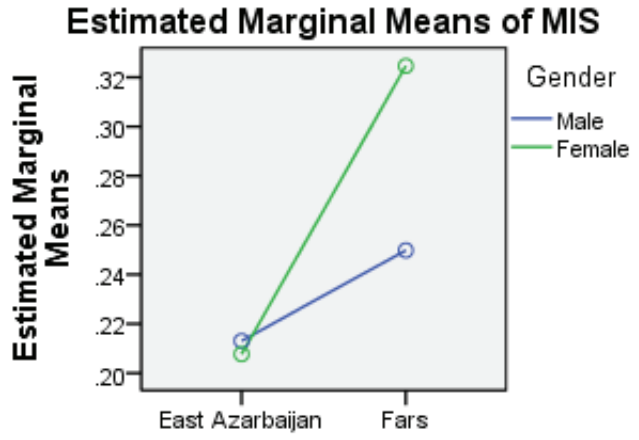

Province

Figure 2. Utilization of outpatient services based on the enrollees' gender in the two provinces

nificantly higher among enrollees of the Fars province in four types of services. According to the results of this test, utilization of PM was also higher among women than men. The SSV utilization rate was higher among enrollees in the $56-65$ and $\geq 65$ age groups than those in the age groups of $19-25$ and $26-35$. The utilization of PM was higher among < 19-year-old people than others in the 26-35 age group. People in the 56-65 age group also utilized more PM than others in the $26-35$ age group. Finally, the utilization rate of PM was higher among people in the 46-55 and 56-65 age groups than enrollees in the 26-35 age group. Regarding utilization of LS, this amount for the enrollees in the 56-65 age group was higher than others in the < 19, 26-35 and $36-45$ age groups. The rate of MIS utilization was higher for people in the 56-65 and $>65$ age groups than others $<19$ years of age. Enrollees $>65$ years of age also used more MIS than others in the $26-35$ age group $(p<0.05)$.

\section{MANOVA}

The status of service utilization based on the enrollees' gender in the two provinces is shown in Figure 2. The utilization of all types of services for men and women, except SSV among men, in Fras was higher than in East Azerbaijan. While the GLM-MANOVA results showed that there was a significant association between gender and utilization of PM, in the Fras province, women utilized all four types of services more than men. In East Azerbaijan, women utilized more PM, and the utilization of other services was higher in men.

\section{Discussion}

The Iranian Health system has been implementing UFPP since 2012 as a pilot project in two provinces aimed at control- 
ling cost, improving efficiency, waste prevention, reduction of unnecessary referrals to specialists and subspecialists, equality in access, enhancement of the responsiveness of the health system and health promotion $[15,16,26,33]$. Most existing studies examining the effectiveness of this program are in the field of client knowledge about UFPP, satisfaction with the program and its implementation, as well as investigations into challenges in policy and practice within the program [34-38].

The utilization of outpatient services was compared in the urban population of the Fars province and a corresponding province. The results showed that the utilization of SSV, PM, LS and MIS was higher among enrollees of the Fars province than among those from East Azerbaijan. The results of the $t$-test confirmed the difference between the two provinces in terms of utilization of PM, LS and MIS. By adjusting the effect of enrollee' age and gender through multivariate analysis, the difference between the two provinces was also confirmed regarding SSV utilization.

In this regard, the studies conducted in different countries reached distinct results. According to Dumontet et al., the rate of specialist visits has dropped by $5 \%$, and the expenditure associated with visiting a specialist has also decreased by $2 \%$ following the implementation of gatekeeping reform in France in 2005 [39]. In line with the results obtained in France, Bastos et al. concluded that having a regular physician led to low utilization of services in southern Brazil [40]. However, in contrast with the two studies mentioned above, Thanah and Rapoport concluded that having a regular doctor would increase the utilization of the services in Canada. They have argued their unexpectable findings on the basis of two possible scenarios: CoC cannot lead to a reduction in utilization of specialized services and having a regular doctor does not provide continuity of care [20].

In Iran is little evidence in Iran about the effect of family physician program on service utilization. The results of a study conducted by Barati et al. have shown a decrease in the utilization of laboratory and medical imaging services [27]. The findings of the present study are inconsistent with the mentioned study in Fars. This contradiction suggests two probabilities. The first is the difference between the approaches by studies to determine the effectiveness of the program. In the mentioned study, the status of utilization of services was compared in the first eight months of UFPP implementation with the same period as in the previous year. The second is that the investigation of the outcomes of UFPP in the study by Barati et al. immediately after starting the program may not have reached reliable results. Population-based programs are time consuming in terms of the consequences [41]. The results of a study by Honarvar et al. in the Fars province revealed a low level of people's knowledge and practice toward their rights in UFPP after two years of UFPP implementation [34], which shows that it takes time for the consequences of the program to be realized.

The results of this study are inconsistent with prevailing literature that states FPP can reduce unnecessary specialized services $[4-7,18,19,39,40]$. It has been argued that, on the one hand, FPP can maintain $\mathrm{CoC}$, thereby reducing unnecessary services $[24,25]$. On the other hand, having a family doctor promotes patient awareness in choosing the preferred care pathway [39]. Jahromi et al. concluded that $\mathrm{CoC}$ is suitable in the Fars province from some aspects; however, there are many problems that limit the effectiveness of UFPP in this regard [23]. Accordingly, it is expected that some conditions will be provided to reduce utilization of services, but the results of the present study are inconsistent with this allegation. There are various possibilities for these results. First, there may be problems in the implementation of the program that hinder its effectiveness, such as the high prevalence of self-referral, which certainly has an effect on increasing utilization of services [26], as well as low client satisfaction with outpatient services through UFPP, which affects their compliance with program requirements and the referral system [36].
In the interpretation of the results, the second possibility relates to the certainty of relationships between having FP, CoC and a reduction of utilization of services. According to Rogers and Curtis, CoC includes many dimensions [42], which, as Thanah and Rapoport argued, regular doctor can not meet all dimensions of $\mathrm{CoC}[20]$. The third possibility is that the greater utilization of services in the Fras province was due to improved access, which, in this case, does not mean unnecessary utilization. In line with this claim, Khedmati et al. concluded that RFPP and UFPP in Iran improved access to health care [43]. One of the signs of improved access in this study is the differences in service utilization between men and women in the two studied provinces. Based on the results represented in Figure 2, in East Azerbaijan, men utilize SSV, LS and MIS more than women, whereas in the Fars province, women utilized all four services more than men, which may have been due to improved access in the Fars province. Women in developing countries, as well as Iran, are facing barriers to accessing health care, especially financial constraints $[44,45]$. Therefore, the reason for the high utilization of services in the Fars province can be attributed to the improvement of access to health care, especially for women. UFPP also increases the utilization capability of poor people by reducing the cost of services and so reducing the gap between the poor and the rich, which can also lead to increased access for poor people and greater utilization of services.

Multivariate analysis revealed a significant difference between age groups and utilization of services in such a way that the elderly utilized more services than others. Greater utilization of services among older people has already been confirmed [46]. Older people suffering from non-communicable diseases and multi-morbidity are especially exposed to high service utilization [47].

As an advantage and strength, it can be stated that this is the first comparative study to examine the effect of UFPP on utilization of services, which provides a rational insight for healthcare policymakers. The selection of matching provinces through clustering can increase the accuracy of comparison and the acceptability of the results. However, there are limitations to this study. The first limitation is that the study's cross-sectional design precludes concluding causalities. Another limitation is a lack of data related to utilization before the implementation of UFPP in both provinces. In this case, statistical analysis was carried out by controlling the baseline data, and the results were more genuine. The third limitation of the study is that although the East Azerbaijan province was matched with the Fars province on the basis of a set of indicators, the role of cultural factors in utilization of services cannot be denied. Therefore, further research, especially longitudinal studies with the possibility of comparing several provinces, is suggested to clarify the effects of UFPP on utilization rate.

\section{Conclusions}

The results of this study showed that utilization of outpatient services in the Fars province was higher than in East Azerbaijan. Since this study was conducted five years after the implementation of UFPP, it is expected that the program has reduced specialized services. Available scientific evidence also frequently confirms the effects of FPP on reducing the use of specialized services, but the findings of this study are somewhat surprising. One possible explanation could be that this has been the result of improvements in access to health care by removing financial barriers, especially for women and poor people. Another probabilistic explanation is that the goals of the program have not been achieved because of the structural and executive problems and challenges, especially in the field of outpatient services. Accordingly, a critical review of the program and its executive approach is recommended. 
Acknowledgements. This article is a part of a PhD thesis supported by Tabriz University of Medical Sciences [Thesis No. $314 / \mathrm{D} / \mathrm{M}]$. We would like to thank all the staff of IHIO who assisted us with this study.

Abbreviations. $\mathrm{Cl}$ - confidence interval; $\mathrm{CoC}$ - continuity of care; EMR - Eastern Mediterranean Region; FP - family physi- cian; FPP - family physician plan; GLM-MANOVA - general linear model-multivariate analysis of variance; IHIO - Iranian Health Insurance Organization; LS - laboratory services; MD - mean difference; MIS - medical imaging services; PHC - primary health care; PM - prescribed medicine; RFPP - rural family physician plan; RHCs - rural health centers; SSV - specialist/subspecialist visit; UFPP - urban family physician plan; UHCs - urban health centers.

Source of funding: This work was funded from the authors' own resources.

Conflicts of interest: The authors declare no conflicts of interest.

\section{References}

1. Gillam S. Is the declaration of Alma Ata still relevant to primary health care? BMJ 2008; 336(7643): 536-538.

2. Politzer RM, Schempf AH, Starfield B, et al. The future role of health centers in improving national health. J Public Health Policy 2003; 24(3-4): 296-306.

3. Gorji HA, Royani S, Mohseni M, et al. Primary health care quality in Iran: a systematic review and meta-analysis. Fam Med Prim Care Rev 2019; 21(1): 71-77.

4. Franks P, Fiscella K. Primary care physicians and specialists as personal physicians: health care expenditures and mortality experience. J Fam Pract 1998; 47(2): 105-110.

5. Starfield B, Shi L, Macinko J. Contribution of primary care to health systems and health. Milbank Q 2005; 83(3): 457-502.

6. Siddiqi S, Kielmann A, Khan M, et al. The effectiveness of patient referral in Pakistan. Health Policy Plan 2001; 16(2): $193-198$.

7. Casanova C, Starfield B. Hospitalizations of children and access to primary care: a cross-national comparison. Int J Health Serv 1995; 25(2): 283-294.

8. Arab-Zozani M, Pezeshki MZ, Khodayari-Zarnaq R, et al. Balancing overuse and underuse in the Iranian Healthcare System: a force field theory analysis. Ethiop J Health Sci 2019; 29(2): 231-238.

9. Feyzabadi VY, Ansari M, Rarani MA, et al. Health team in primary health care: facilitators and inhibitors of the effective function. Journal of Management and Medical Informatics School 2014; 2(1): 74-66.

10. Heshmati B, Joulaei H. Iran's health-care system in transition. Lancet 2016; 387(10013): 29-30.

11. Asadi-Lari M, Sayyari A, Akbari M, et al. Public health improvement in Iran: lessons from the last 20 years. Public Health 2004; 118(6): 395-402.

12. Malekafzali H. Primary health care in the rural area of the Islamic Republic of Iran. Iranian Journal of Public Health 2009; 38(Suppl. 1): 69-70.

13. Mehrdad R. Health system in Iran. JMAJ 2009; 52(1): 69-73.

14. Arab-Zozani M, Sokhanvar M, Kakemam E, et al. History of health technology assessment in Iran. Int J Technol Assess Health Care 2020; 36(1): 34-39, doi: 10.1017/S0266462319003489.

15. Takian A, Doshmangir L, Rashidian A. Implementing family physician programme in rural Iran: exploring the role of an existing primary health care network. Fam Pract 2013; 30(5): 551-559.

16. Ministry of Health and Medical Education (MOHME). Guidance to urban family physician program. Tehran: MOHME; 2012.

17. Niyas M, Karimi M, Kavosi Z. Utilization of primary health care services in rural and urban areas in Shiraz. Shiraz E Medical Journal 2018, doi: 10.5812/semj.66219.

18. Garrido MV, Zentner A, Busse R. The effects of gatekeeping: a systematic review of the literature. Scand J Prim Health Care 2011; 29(1): 28-38.

19. Khoja TA, Al Shehri AM, Abdul Aziz AAF, et al. Patterns of referral from health centres to hospitals in Riyadh region. EMHJ - Eastern Mediterranean Health Journal 1997; 3(2): 236-243.

20. Thanh NX, Rapoport J. Health services utilization of people having and not having a regular doctor in Canada. Int J Health Plann Manage 2017; 32(2): 180-188.

21. Delnoij D, Van Merode G, Paulus A, et al. Does general practitioner gatekeeping curb health care expenditure? J Health Serv Res Policy 2000; 5(1): 22-26.

22. Jahromi VK, Dehnavieh R, Mehrolhassani MH, et al. Access to healthcare in urban family physician reform from physicians and patients' perspective: a survey-based project in two pilot provinces in Iran. Electronic Physician 2017; 9(1): 3653-3659.

23. Jahromi VK, Mehrolhassani MH, Dehnavieh R, et al. Continuity of care evaluation: the view of patients and professionals about urban family physician program. Int J Prev Med 2017; 8: 7, doi: 10.4103/2008-7802.200525.

24. Bayliss EA, Ellis JL, Shoup JA, et al. Effect of continuity of care on hospital utilization for seniors with multiple medical conditions in an integrated health care system. Ann Fam Med 2015; 13(2): 123-129.

25. Guthrie B, Saultz JW, Freeman GK, et al. Continuity of care matters. BMJ 2008; 337: a867.

26. Kavosi Z, Siavashi E. A study of the performance of referral system in urban family physician program in Fars Province, Iran. $J$ Health Man Info 2018; 5(3): 88-95.

27. Barati O, Pourmohammadi K, Zakeri M. Survey of the demand trend for para-clinic services after family physician plan in Fars province. Hakim Research Journal 2016; 19(1): 58-63.

28. Dastgerdi MV. Islamic Republic of Iran's Health System: achievements and prospective. Iranian Journal of Public Health 2013; 42 (Suppl. 1): $1-2$.

29. Iranian Health Insurance Organization (IHIO). Performance report, 2016. Available from URL: https://ihio.gov.ir (in Persian).

30. Statistical Center of Iran. Report of population and housing census, 2016. Available from URL: https://wwwamarorgir/english/Population-and-Housing-Censuses.

31. Davies DL, Bouldin DW. A cluster separation measure. IEEE Trans Pattern Anal Mach Intell 1979; 1(2): 224-227.

32. Davis WJ. Handbook of univariate and multivariate data analysis and interpretation with SPSS. Am Stat 2008; 62: 268.

33. Damari B, Moghaddam AV, Gooran NR, et al. Evaluation of the urban family physician and referral system program in Fars and Mazandran provinces: history, achievements, challenges and solutions. Journal of School of Public Health and Institute of Public Health Research 2016; 14(2): 17-38.

34. Honarvar B, Lankarani KB, Rostami S, et al. Knowledge and practice of people toward their rights in urban family physician program: a population-based study in Shiraz, Southern Iran. Int J Prev Med 2015; 6(1): 46. 
35. Honarvar B, Lankarani KB, Ghahramani S, et al. Satisfaction and dissatisfaction toward urban family physician program: a population based study in Shiraz, Southern Iran. Int J Prev Med 2016; 7(1): 3.

36. Mirahmadizadeh A, Marzban M, Siadati M, et al. Client satisfaction with urban family physician and referral system in the South of Iran: a repeated cross-sectional study. Journal of Health Sciences \& Surveillance System 2017; 5(2): 72-78.

37. Behzadifar $M$, Behzadifar $M$, Heidarvand $S$, et al. The challenges of the family physician policy in Iran: a systematic review and metasynthesis of qualitative researches. Fam Pract 2018; 35(6): 652-660.

38. Bahramali E, Firouzabadi N. Missed links in the determination of challenges of urban family physician program response. Arch Iran Med 2018; 21(10): 488.

39. Dumontet $\mathrm{M}$, Buchmueller T, Dourgnon $\mathrm{P}$, et al. Gatekeeping and the utilization of physician services in France: evidence on the Médecin traitant reform. Health Policy 2017; 121(6): 675-682.

40. Bastos GAN, Duca GFD, Hallal PC, et al. Utilization of medical services in the public health system in the Southern Brazil. Revista de Saúde Pública 2011; 45(3): 475-484.

41. McCoy-Thompson M. The Healthy Start Initiative: a community-driven approach to infant mortality reduction. Vol. II. Early Implementation. Lessons Learned: ERIC; 1994.

42. Rogers J, Curtis P. The concept and measurement of continuity in primary care. Am J Public Health 1980; 70(2): $122-127$.

43. Khedmati J, Davari M, Aarabi M, et al. Evaluation of urban and rural Family Physician Program in Iran: a systematic review. Iranian Journal of Public Health 2019; 48(3): 400.

44. Ojanuga DN, Gilbert C. Women's access to health care in developing countries. Soc Sci Med 1992; 35(4): 613-617.

45. Kokabisaghi F. Women's right to health in Iran: domestic implementation of international human rights law. Int J Health Plann Manag 2019; 34(2): 501-509.

46. Vegda K, Nie JX, Wang L, et al. Trends in health services utilization, medication use, and health conditions among older adults: a 2-year retrospective chart review in a primary care practice. BMC Health Serv Res 2009; 9(1): 217.

47. Janković J, Šiljak S, Marinković J, et al. Patterns of health care utilization for noncommunicable diseases in a transitional european country: results from the National Health Survey. Int J Health Serv 2019; 49(1): 37-50.

Tables: 3

Figures: 2

References: 47

Received: 24.12 .2019

Reviewed: 30.12 .2019

Accepted: 27.01.2020

Address for correspondence:

Ali Janati, PhD, Assoc. Prof.

Iranian Center of Excellence in Health Management

School of Management and Medical Informatics

Tabriz University of Medical Sciences

Tabriz

Iran

Tel.: +989144195377

E-mail: janati1382@gmail.com 